\title{
Metocean Criteria for Internal Solitary Waves Obtained from Numerical Models
}

\author{
Liaqat Ali ${ }^{1, *(\mathbb{D})}$, Nageena Makhdoom ${ }^{1}$, Yifan Gao ${ }^{1} \mathbb{D}$, Pan Fang ${ }^{2}$, Sikandar Khan ${ }^{3}$ (D) and Yong Bai ${ }^{1}$ \\ 1 College of Civil Engineering \& Architecture, Zhejiang University, Hangzhou 310058, China; \\ 11912135@zju.edu.cn (N.M.); y.f.gao@zju.edu.cn (Y.G.); baiyong@zju.edu.cn (Y.B.) \\ 2 Department of Maritime and Transport Technology, Delft University of Technology, AA 2600 Delft, \\ The Netherlands; P.Fang-1@tudelft.nl \\ 3 Department of Mechanical Engineering, King Fahd University of Petroleum and Minerals, Dhahran 31261, \\ Saudi Arabia; sikandarkhan@kfupm.edu.sa \\ * Correspondence: drali169@zju.edu.cn
}

Citation: Ali, L.; Makhdoom, N.; Gao, Y.; Fang, P.; Khan, S.; Bai, Y. Metocean Criteria for Internal Solitary Waves Obtained from Numerical Models. Water 2021, 13, 1554 https:/ / doi.org/10.3390/w13111554

Academic Editor: Shin-Jye Liang

Received: 11 April 2021

Accepted: 28 May 2021

Published: 31 May 2021

Publisher's Note: MDPI stays neutral with regard to jurisdictional claims in published maps and institutional affiliations.

Copyright: (C) 2021 by the authors. Licensee MDPI, Basel, Switzerland. This article is an open access article distributed under the terms and conditions of the Creative Commons Attribution (CC BY) license (https:// creativecommons.org/licenses/by/ $4.0 /)$

\begin{abstract}
A numerical model in slice configuration was applied to the Central Andaman Sea in order to derive metocean operational and design criteria associated to internal solitary waves which are large amplitude interfacial waves. For that purpose, a 10 year hindcast was generated. The model was driven by tides at the open boundary and included realistic stratification and topography. The results have been compared to data mostly taken from satellites and proved to be accurate in determining parameters such as phase speed and interpacket distance. The phase speeds range from $2.21 \mathrm{~m} / \mathrm{s}$ in March to $2.5 \mathrm{~m} / \mathrm{s}$ in November. Corresponding interpacket distances range from $99 \mathrm{~km}$ to $111 \mathrm{~km}$ in close agreement with available data. According to the model results internal solitary waves are more/less frequent in March/August. Model outputs were specifically analyzed at 2 arbitrary locations. Maximum current speeds obtained with the model at those locations occur in November reaching a value close to $1.5 \mathrm{~m} / \mathrm{s}$. The computed velocities associated to return periods of $1,10,50,100$ and 1000 years are, respectively, $1.67 \mathrm{~m} / \mathrm{s}, 1.76 \mathrm{~m} / \mathrm{s}, 1.8 \mathrm{~m} / \mathrm{s}, 1.81 \mathrm{~m} / \mathrm{s}$ and $1.84 \mathrm{~m} / \mathrm{s}$.
\end{abstract}

Keywords: internal solitary waves; numerical modelling; extreme criteria; Andaman Sea

\section{Introduction}

Internal waves (IWs) are waves travelling within the interior of a fluid with vertical density gradients. In a two-layer fluid, these are generally, slow large amplitude waves that propagate along the interface between the two fluids. The existence of internal waves is due to the sharp density gradient. In the ocean, there are important vertical variations of the density and therefore any disturbance of the pycnocline will propagate away as an internal wave [1]. In other words, in the ocean the vertical stratification provides a restoration force that in response to external forcing such as wind and tide leads to the generation of internal waves (IWs). IWs are able to travel for hundreds of kilometers, sometimes inducing strong currents in the upper layers of the ocean.

Internal waves can be found in the coastal and marginal waters of the world's oceans [2]. Most of them come from nonlinear steepness of internal tides that occur when tides flow through sudden terrain, such as broken shelves or undersea ridges. After generation, ISWs can last for days and travel up-to $100 \mathrm{~km}$ till they slide into shallow water. In the shoal phase, ISW can split into numerous waves, reverse its polarity, also break, all of which induce strong as well as rapid turbulence to dissipate and mix [3-7]. Turbulence caused by internal tides is known to cause mixed water masses, which then flow into the vast sea also dissipate much of the world's oceans [8,9]. Due to ISW's role in channelling tidal energy to small-scale turbulence, a better considerate of the physical principles of energy dissipation and mixing throughout the ISWs process from generation to shoal may help to better mix as well understand energy budgets in global ocean also 
climate models. In the marine atmosphere, ISWs-related energy flows and turbulence can resuspend sediments [10-14], alter acoustic transmission [15-17], destroy offshore engineering structures [18] and affect inshore ecosystems [19-21]. The world's strongest internal waves has been noticed in the Andaman Sea and South China Sea [22-24], with vertical also horizontal velocities greater than 2 and $0.5 \mathrm{~m} \mathrm{~s}^{-1}$, correspondingly, with amplitudes of $100-200 \mathrm{~m}$.

A particular class of IWs are the internal solitary waves (ISWs). They are important where strong tidal flows are combined with stratification and steep topography. ISWs can produce currents larger than $1 \mathrm{~m} / \mathrm{s}$ and have the capability to pose important risks for offshore industry. As an example, ISWs are potentially hazardous to subsea gas and oil drilling operations. A comprehensive description of ISWs characteristics, their occurrence in the ocean and theoretical considerations can be found in Jackson [25].

The IWs can create periodic shear load of high magnitude that can cause fatigue damage to offshore structures [26-31]. During the process of carbon dioxide capture and storage, carbon dioxide could be deliberately injected into the ocean at great depth. The captured carbon dioxide is transported by means of pipelines for injection in the ocean. These pipelines should be properly designed, in order to prevent any possible damage from the periodic shear load of the IWs [32-36].

Incidents involving ISWs have happened in the past, such as the one on 10th April 1986 with drillship SEDCO 445 (Shell Company, Hague, The Netherlands) in South Andaman Sea, with significant impacts on drilling operations. The Andaman Sea, the focus of this paper, is a marginal sea of north-eastern Indian ocean located between the Myanmar and Thailand coastlines and the Andaman and Nicobar Islands. As many other types of IWs, ISWs can propagate for hundreds of kilometres in the ocean. The most important characteristics of ISWs such as propagation speed, time of arrival, frequency of events, seasonality, associated ocean currents and their return periods are frequently required by offshore industry.

Robust statistics of the ISWs parameters are only possible if long time series of currents are available. To derive a range of return periods time series of the order of at least 10 years are required. As usual when it comes to ocean currents those data are not available from measurements. Further to capture the ISWs characteristics sampling periods of the order of $1 \mathrm{~min}$ are necessary. Therefore, approaches such as numerical modelling or synthetic generation are required to generate such datasets.

In order to model ISWs, one needs to combine high spatial resolution with the capability to incorporate nonlinear and nonhydrostatic processes. The classical 3D ocean models are computationally expensive and in practice almost impossible to use. An alternative approach is to use a 2D-V configuration as presented by Ali et al. [37] for the Sulu Sea. This approach makes possible the generation of large datasets while keeping the required physics and vertical and horizontal resolutions.

A similar approach has been used in a process study over the Mascarene Ridge in the Indian Ocean by a Silva et al. [38]. It must be noted that this configuration only works for regions that are affected by ISWs generated at one source.

A complete analysis of model applications to the South China sea has been provided by Simmons et al. [39]. This analysis included numerical, empirical and analytical approaches and allowed the identification of models with predictive character. Those include the empirical model from Jackson [40], the application of SUNTANS model by Zhang et al. [41] and the isopycnal RHIMT model by Alford et al. [42]. The empirical model proposed by Jackson [40] is a 2D plan view model that uses information from surface signatures of ISWs, seen in satellite imagery, to calculate the parameters that allow the computation of phase speed as a function of water depth. The model allows the estimation of travelling time between the source and any location as well as the propagation path. The parameters of the model are estimated to minimize the error between calculated and observed (in satellite imagery) propagation times. The RMS error produced in arrival times is $1.32 \mathrm{~h}$ for ISWs observed in water depths larger than $1000 \mathrm{~m}$ and $2.55 \mathrm{~h}$ for water depths between $200 \mathrm{~m}$ and 
$1000 \mathrm{~m}$. The paper by Zhang et al. [41] describes the application and the results obtained with SUNTANS model (for a description of SUNTANS see Fringer et al. [43]). SUNTANS is a 3-D non-hydrostatic model that uses an unstructured grid. The model was driven by barotropic tides at the open boundary and used realistic topography and stratification to simulate the generation and propagation of ISWs in the South China Sea. Results include accurate prediction of arrival times particularly in deep water. For small to moderate amplitude waves the model underpredicted internal wave amplitudes by $30 \%$ but the error increases for more than $50 \%$ for larger amplitudes. The error seems to be related to lack of model resolution which was of the order of $1.5 \mathrm{~km}$. Note that even with such a resolution, the model took seven days on 64 processors to compute a 16-day prediction. This means that model results can only be used to understand the physical processes involved on generation and propagation of ISWs. The application of RHIMT has been described by Alford et al. [42]. Realistic topography has been used while for stratification a horizontally uniform field has been adopted. One of the major advantages of RHIMT, when compared to SUNTANS, is that it uses isopycnal coordinates which are able to produce physically meaningful results with as few as two layers. Therefore, RHIMT is much faster than SUNTANS. In terms of the results obtained they are equivalent to SUNTANS: accurate predictions of arrival time and poor representation of wave amplitudes.

The synthetic generation of long time series has been presented in Jeans et al. [44] and Jeans et al. [45]. In Jeans et al. [44] the use of Nonlinear Fourier Analysis Spectral Tools (NFAST) allowed the quantification of ISWs. The current speeds derived from interface displacements via temperature measurements were validated against measured data. The technique has been applied to generate ISWs speeds for a period of 100 years suitable for design criteria.

In this paper the 2D-V approach is applied to the Central Andaman Sea located in the Indian Ocean. The choice for this area is since it is well known the generation of internal tides in the Ten Degree Channel between the Nicobar and Andaman Islands. Therefore, the Central Andaman Sea serves the purpose of this paper which to derive operational and design criteria from realistic currents produced by non-hydrostatic $2 \mathrm{D}-\mathrm{V}$ models. The 2D-V approach consists of applying a two-dimensional model whose directions are the longitudinal (in this case the wave propagation direction) and the vertical. The approach has been used by Buijsman et al. [46] using the non-hydrostatic version of the Regional Ocean Modelling System (ROMS) to study the generation and propagation in the South China Sea. Another application has been done by da Silva et al. [38] for the Mascarene Plateau. In a previous paper by Ali et al. [37] the approach was validated against literature data for the Sulu Sea. The model was applied in a non-hydrostatic configuration using realistic topography and stratification and was driven by tidal components at the open boundaries. The whole point was to prove that a $2 \mathrm{D}-\mathrm{V}$ non-hydrostatic model with much higher resolution than classical the 3D models was accurate enough to predict arrival time, wave amplitude and associated currents. Further, it was shown that the generation of a 10 year hindcast was achievable given the computational time required to run the model. In this paper the 10 year hindcast was actually generated and metocean criteria was derived from the model data. To our knowledge, this is the first time that a 10 year hindcast with appropriate resolution was developed with the purpose of deriving metocean criteria associated to ISWs propagation.

The research article is prepared as follows: Section 2 describes methodology followed to generate long time series of currents due to ISWs. The numerical model is also labelled; Section 3 describes a selection of data collected in the Central Andaman Sea allowing the identification of the generation locations. The model results are presented. Section 4 provides a discussion on the validity of the model results and a comparison with available literature. Lastly, Section 5 presents the major conclusions of the work done and the implications of the results obtained. 


\section{Research Methods}

To apply a numerical model in the 2D-V configuration the source area for ISWs needs to be determined prior to model setup. The generation areas will be analysed later in Section 3 based on published literature.

Once the location for the generation is confirmed, a section of the central Andaman Sea is selected to be simulated using a non-hydrostatic version of the Delft3D-FLOW model version 3.15 (Deltares, Delft, The Netherlands). Delft3D-FLOW solves time-dependent, three-dimensional, non-linear differential equations. These are solved for both, hydrostatic and non-hydrostatic free-surface flow problems. Complicated geometry problems are handled by a structured orthogonal grid. As a general case, the equations are formulated in orthogonal curvilinear co-ordinates and models with a rectangular or spherical grid (Cartesian frame of reference) are considered as a special form of a curvilinear grid Kernkamp et al. [47].

Additionally, the model solves the volume (continuity), heat and salt conservation equations. A state equation that relates temperature and salinity to density is also necessary. Finally, the turbulent kinematic viscosities are computed by means of a turbulent closure model. For this application the $\mathrm{k}-\varepsilon$ closure was used.

Delft3D-FLOW can be used in also hydrostatic or non-hydrostatic modes. If choose hydrostatic modelling, the so-called shallow water equation that was previously carved is solved, wherein in non-hydrostatic mode, the Navier-Stokes equation is considered by adding non-hydrostatic terms to the shallow water equation. A fine horizontal mesh is needed to solve the phenomenon of non-hydrostatic water flow.

The advantages and disadvantages of different modelling approaches were mentioned in Ali et al. [37] who discusses the application of MITgcm, Marshall et al. [48] and SUNTANS, Fringer et al. [43]. The major goal here is to produce a reliable dataset covering a period large enough to derive metocean criteria, particularly the expected current speeds for relevant return periods.

The model setup follows the description made in Ali et al. [37]. A resolution of $100 \mathrm{~m}$ was adopted together with a vertical discretization in 68 layers. The vertical resolution was enhanced in the upper $200 \mathrm{~m}$. However, the maximum resolution is at surface where a $5 \mathrm{~m}$ layer was considered. One of the major limitations of models simulating the generation and propagation of ISWs is the horizontal resolution applied. In fact, the resolution needs to be sufficient to describe the small-scale processes involved both on generation and propagation. On the other hand, a very high resolution compromises the feasibility of the simulations by limiting the time step to be used and therefore demanding very large computational times. Another problem that relates to the horizontal resolution is the numerical dispersion. Particularly in non-hydrostatic models, attention must be paid to the leptic ratio (which is given by the ratio between the horizontal resolution and the depth of the surface mixed layer). When the leptic ratio exceeds 1 the numerical dispersion exceeds the physical dispersion and modelled internal waves exist with a dynamical balance between nonlinearity and numerical dispersion. Vitousek and Fringer [49] addressed this problem. With the resolution chosen here, the leptic ratio is close to 1.

The initial conditions considered were the monthly averaged temperature and salinity profiles taken from the World Ocean Atlas 2018, Boyer et al. [50]. Initial velocity and water level were set to zero. The boundary conditions applied to the western boundary are the water levels computed from the tidal components extracted from TPXO9.0 (CEOAS Oregon State University, Corvallis, OR, USA), Egbert and Erofeeva [51] and the salinity profiles as well as temperature that are also taken from the 2018 World Ocean Atlas. At the eastern boundary, a radiation condition was applied to allow the waves generated inside the model domain to propagate outwards. The model was integrated for 10 years with reinitializations at every month meaning that 120 runs were performed with initial conditions taken from monthly climatological profiles for temperature and salinity. A small spin-up period of 5 days was considered at every initialization although it is discarded in the analysis. 
In order to validate the numerical model one of the resources available are estimates of phase speed and interpacket distances published in literature. Tensubam et al. [52] analysed pairs of Synthetic Aperture Radar (SAR) form tandem satellites such as ERS2 and EnviSat and MODIS, Visible Infrared Imaging Radiometer Suite (VIIRS) and Medium Resolution Imaging Spectrometer (MERIS) for a period of nearly 14 years between December 2002 and May 2016. They have found that ISWs are concentrated in 4 different regions of the Andaman Sea: in the south eastern part near Sumatra, the central eastern region, around Nicobar Islands and in the northern region. Amongst other findings Tensubam et al. [52] reported a decrease in phase speed with decreasing depth and significant differences between January/December and March that the authors attribute to changes in the ocean stratification and mixed layer depth. In the Central Andaman Sea, they reported average interpacket distances between $92.5 \mathrm{~km}$ and $125.6 \mathrm{~km}$ with phase speeds ranging from $2.06 \mathrm{~m} / \mathrm{s}$ and 2.89 respectively. The phase speeds estimated from satellite imagery by Tensubam et al. [52] are in good agreement with phase speeds estimated from the SturmLiouville equation using climatological stratification and realistic bathymetry of the area. da Silva and Magalhaes [53] have estimated $2.37 \mathrm{~m} / \mathrm{s}$ for the phase speed of mode-1 waves with interpacket distance of $106 \mathrm{~km}$. Estimates from Sun [49] in the south Andaman Sea have provided values ranging from 2.35 to $2.65 \mathrm{~m} / \mathrm{s}$ for the phase speed of long-lived mode-1 waves.

\section{Results}

The sources of ISWs in the Andaman Sea have been studied by a wide range of authors over the last 30 years. Recently, based on sunglint optical images of Moderate Resolution Imaging Spectroradiometer (MODIS), Sun et al. [54] have established sources for non-linear ISWs in the Andaman Sea. A similar study was published by Raju et al. [55] to detect the possible potential generation locations of mode-1 long living ISWs. Mode- 1 waves are the most generally observed in the sea and are also the fastest baroclinic waves in the ocean. Additionally known as depression waves due to the associated displacement of isopycnals, they have been frequently observed in SAR images as a positive anomaly in the sea surface height. Mode numbers correspond to the number of zero crossings in the vertical profile of the horizontal current. Therefore Mode- 1 waves only have 1 zero crossing. In both studies, generation locations were identified between Sumatra and Nicobar Islands and between these and the Andaman Islands. Furthermore, a generation location was identified in the North at the shelf break between the Andaman Islands and the Myanmar coastline. Of particular relevance for this study are the generation locations between Nicobar and Andaman Islands where ISWs form and propagate across the central Andaman Sea [55]. In particular, we are interested in location C [55], just south of Car Nicobar Island. This location is in agreement with other findings such as Magalhaes and da Silva [56] and Alpers et al. [57]. The area shows a maximum for the vertically integrated body force as defined by Baines [58], that provides an indication of potential for generation of ISWs by combining tidal flow, bathymetry gradient and stratification. The strong tidal forcing combined with the steep topography produces the conditions for generation south of Car Nicobar Island. As we are interested in long-lived mode-1 waves this location was chosen to be the generation location for our study. Figures 1 and 2 show the bathymetry of the central Andaman Sea and the cross-section used for model simulations. The cross-section was chosen based on the fact that it passes over the generation location and follows the direction of propagation of the Mode-1 ISWs. Two output locations, that represent potential study sites are arbitrarily chosen to the east of the generation location. Three locations are identified in Figures 1 and 2: The westernmost location is the generation site where mode- 1 waves are produced; the two locations to the east are locations where model outputs were analysed in detail and metocean criteria was produced. The distance between the generation and the first output locations is approximately $100 \mathrm{~km}$ which corresponds to nearly the distance between leading wave of the crests. Note that ISW propagate in packets of 2 to 10 waves with wavelengths of 5 to $10 \mathrm{~km}$. The packet length is typically 
15 to $50 \mathrm{~km}$. The leading wave in a packet is typically the one with largest amplitude. The second output location is $40 \mathrm{~km}$ to the east of the first one.

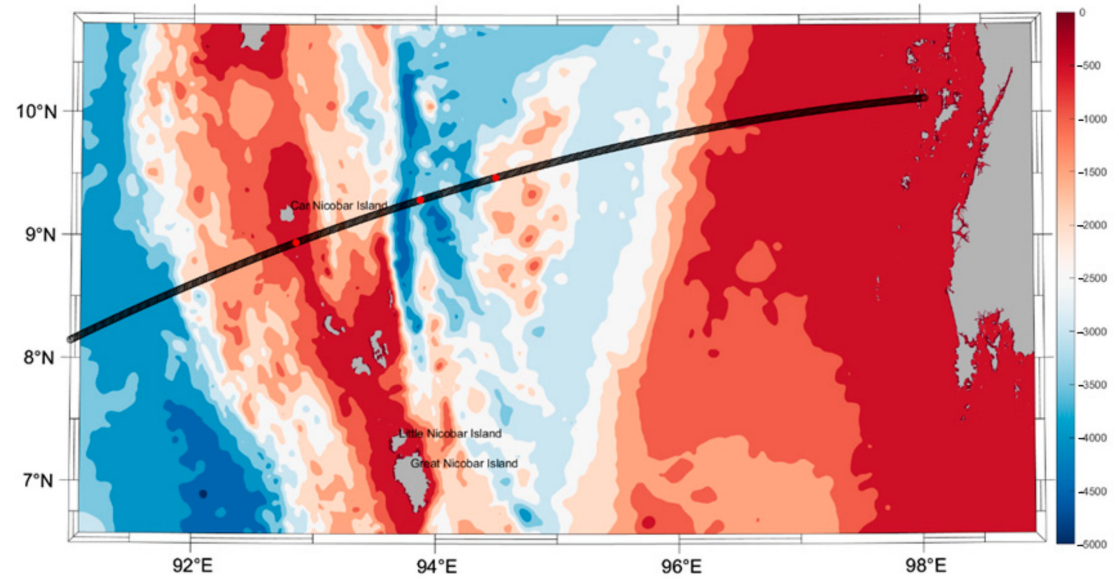

Figure 1. Bathymetry of the Central Andaman Sea. The black line shows the cross-section that is used for the 2D-V modelling. The red dots indicate the generation (westernmost dot) and the model output locations (to the east).

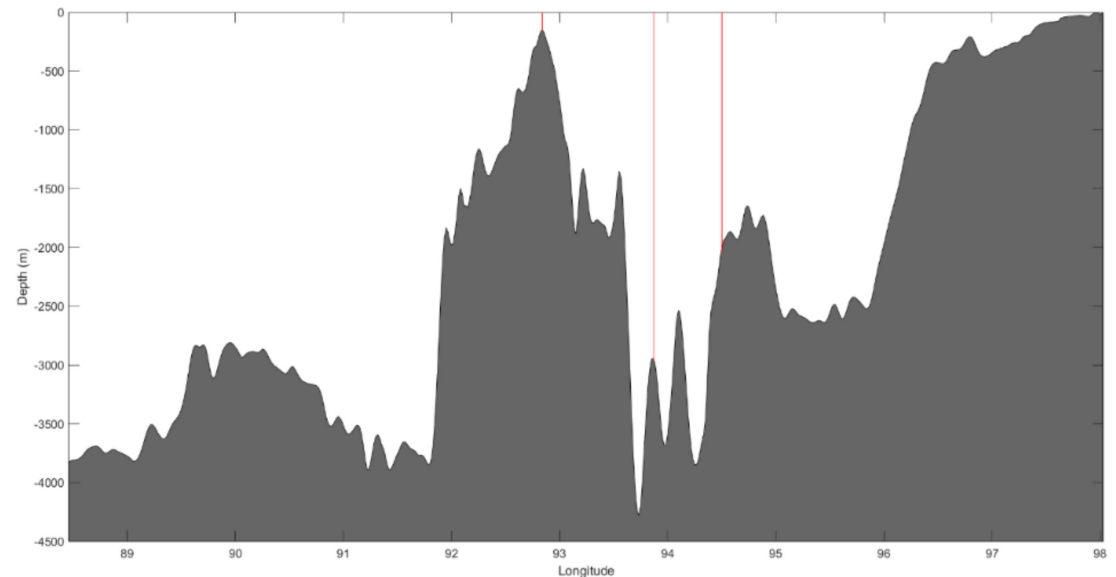

Figure 2. Bathymetry of the cross-section shown in Figure 1 . The vertical red lines show the generation location at approximately $93^{\circ} \mathrm{E}$ and the output locations approximately $100 \mathrm{~km}$ and $140 \mathrm{~km}$ to the east.

As no in-situ data are available for validation purposes, the model was compared to other datasets, mostly taken from satellites, for the Central Andaman Sea, including phase speed, interpacket distances and other relevant characteristics.

In order to estimate the phase speed for long-lived mode- 1 waves time series of currents have been extracted for the 2 locations shown in Figures 1 and 2. The leading waves have been detected by using an algorithm to calculate local maximum acceleration with a threshold of $0.01 \mathrm{~m} / \mathrm{s}^{2}$ at $100 \mathrm{~m}$ depth which has been identified as the level where consistently higher currents are obtained. The time difference between the occurrence of maximum at the two output locations was then used to compute the phase speed since the distance is known. The technique also allows the counting of internal solitary wave events and therefore the establishment of the frequency of their occurrence.

The estimated frequency of events has been monthly averaged over the 10 years. Table 1 summarizes the results derived from the model for phase speed, frequency of events and mixed layer depth at the western output location. In addition, presented are the mixed layer depths extracted for the area from the World Ocean Atlas, Monterey and Levitus [59]. The selected mixed layer depth from World Ocean Atlas is using the 
temperature criteria: a temperature change from the ocean surface of $0.5^{\circ} \mathrm{C}$. The same criteria were adopted to evaluate the mixed layer depth from the model results.

Table 1. Summary of the statistics for some parameters derived from the numerical model: Monthly averaged (over the 10 years) frequency of events, phase speed and its standard deviation and mixed layer depth. In addition, included is the mixed layer depth from the World Ocean Atlas.

\begin{tabular}{cccccc}
\hline Month & Frequency & $\begin{array}{c}\text { Phase Speed } \\
(\mathbf{m} / \mathbf{s})\end{array}$ & $\begin{array}{c}\text { Standard Deviation } \\
\mathbf{( m / s )}\end{array}$ & $\begin{array}{c}\text { Model Mixed Layer } \\
\text { Depth }(\mathbf{m})\end{array}$ & $\begin{array}{c}\text { WOA Mixed Layer } \\
\text { Depth }\end{array}$ \\
\hline January & 35 & 2.35 & 0.026 & 44.0 & 40 \\
February & 34 & 2.33 & 0.030 & 38.5 & 28 \\
March & 45 & 2.21 & 0.052 & 36.3 & 28 \\
April & 34 & 2.23 & 0.055 & 38.2 & 25 \\
May & 28 & 2.46 & 0.040 & 55.0 & 52 \\
June & 30 & 2.44 & 0.050 & 61.4 & 68 \\
July & 18 & 2.35 & 0.084 & 60.0 & 54 \\
August & 10 & 2.37 & 0.031 & 45.5 & 53 \\
September & 33 & 2.48 & 0.017 & 48.5 & 51.6 \\
October & 35 & 2.49 & 0.029 & 46.9 & 53.5 \\
November & 37 & 2.50 & 0.035 & 44.9 & 56 \\
December & 36 & 2.41 & 0.038 & & 35 \\
\hline
\end{tabular}

Other relevant statistics can be derived once the events are isolated and selected. In particular, it is possible to characterize the current speeds associated to ISWs. Table 2 shows the statistics for the maximum speeds associated to each event at the western output location. The statistics for maximum speed were built by selecting the largest current speed in each individual event at $125 \mathrm{~m}$ depth where, typically current is at maximum. Note that maximum speeds are found in November, December and January while minimum are found in July and August with a clear correspondence to the seasonal evolution of the mixed layer depth.

Table 2. Summary of the statistics for maximum event speed. Mean Maximum Speed is the monthly averaged speed of the leading wave obtained from the model at $100 \mathrm{~m}$ depth. The maximum speed is the largest event simulated at each month over the 10 years depth.

\begin{tabular}{lccc}
\hline Month & Mean Maximum Speed $(\mathbf{m} / \mathbf{s})$ & Standard Deviation $(\mathbf{m} / \mathbf{s})$ & Maximum Speed $(\mathbf{m} / \mathbf{s})$ \\
\hline January & 0.68 & 0.23 & 1.34 \\
February & 0.57 & 0.19 & 0.96 \\
March & 0.51 & 0.14 & 0.78 \\
April & 0.72 & 0.21 & 1.17 \\
May & 0.88 & 0.19 & 1.23 \\
June & 0.65 & 0.28 & 1.10 \\
July & 0.20 & 0.16 & 0.53 \\
August & 0.10 & 0.09 & 0.22 \\
September & 0.56 & 0.17 & 0.79 \\
October & 0.76 & 0.19 & 1.12 \\
November & 1.01 & 0.29 & 1.49 \\
December & 0.49 & 0.43 & 1.34 \\
\hline
\end{tabular}

With the identification of maximum events per month over the 10 years of simulation it is also possible to compute the associated vertical profiles and shear which quite important to quantify vertical variation of velocity during extremes. Figure 3 shows the vertical profile corresponding to the maximum velocity observed each month over the 10-year simulation. The structure shown is typical for mode- 1 waves with a maximum speed at the base of the mixed layer and the correspondent maximum shear below the maximum velocity. Typical maximum shear values are in the range 0.02 to $0.04 \mathrm{~L} / \mathrm{s}$. 

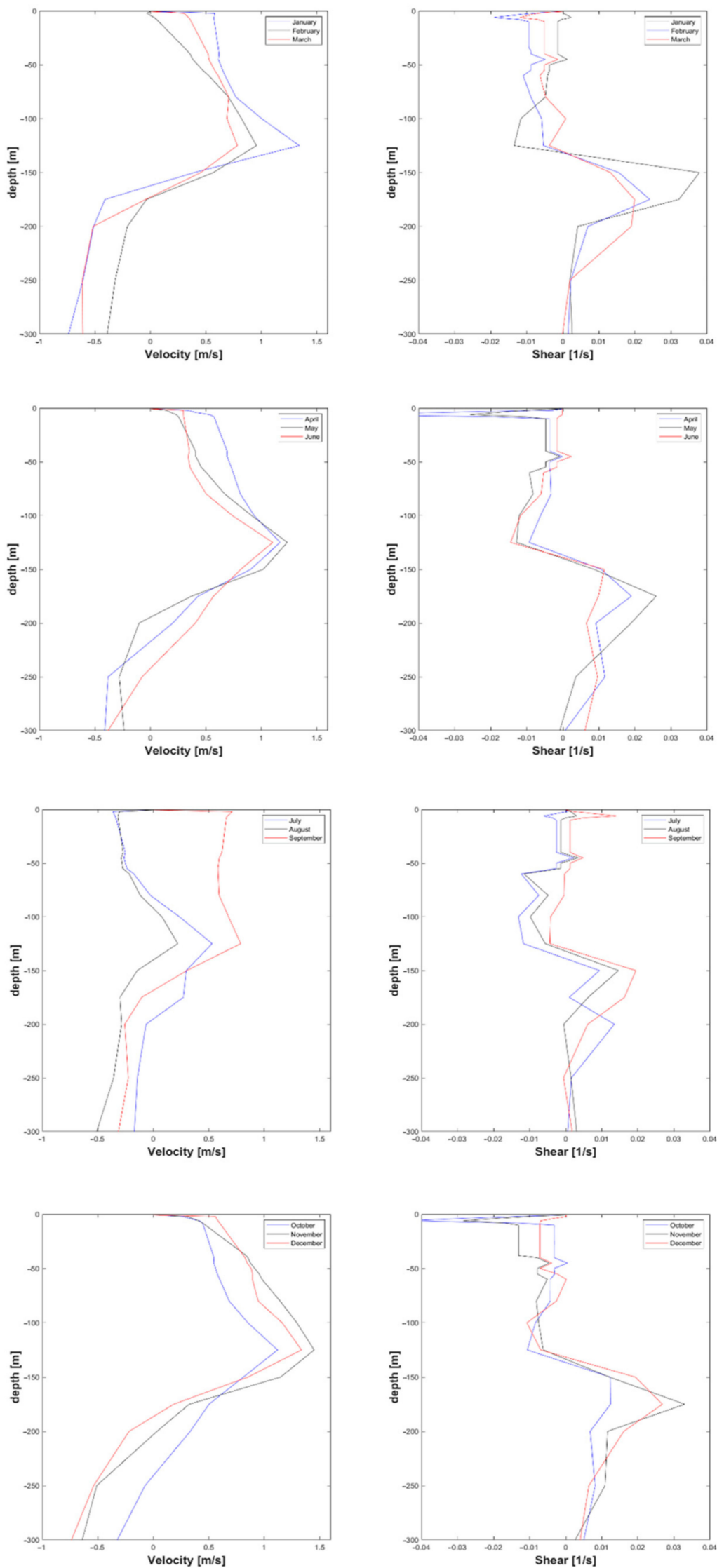

Figure 3. Vertical profiles of velocity (at the western output location in Figures 1 and 2) and shear associated to maximum events for each month. 
Extreme criteria at the western output location for specific return periods were obtained by carrying an extreme value analysis over the 10-year dataset at the depth of $125 \mathrm{~m}$ where maximum velocity is commonly observed. The derivation of extremes was done by using the peaks over threshold method. The threshold is obviously arbitrary, and it was adjusted to better fit the data available. The threshold chosen was $0.8 \mathrm{~m} / \mathrm{s}$. Three distributions were fitted to the time series of event maxima: Weibull, Generalised Pareto and Fisher-Tippet 1. The adjustment used the method of maximum likelihood and the method of moments. The best fit was obtained by using the Generalised Pareto distribution adjusted by the maximum likelihood method and the extreme criteria obtained is shown in Table 3.

Table 3. Extreme criteria for currents for 5 different return periods. Extreme were derived by selecting currents speeds associated to accelerations at the level of maximum acceleration that are above the specified threshold of $0.01 \mathrm{~m} / \mathrm{s}^{2}$.

\begin{tabular}{cc}
\hline Return Period (Years) & Speed $(\mathrm{m} / \mathbf{s})$ \\
\hline 1 & 1.67 \\
10 & 1.76 \\
50 & 1.80 \\
100 & 1.81 \\
1000 & 1.84 \\
\hline
\end{tabular}

\section{Discussion}

The major goal of this work was to derive reliable statistics from long-term time series of currents obtained from numerical models. The Central Andaman Sea was chosen to test the methodology. A 2D-V non-hydrostatic model was used to simulate the generation of ISW south of Car Nicobar Island and their propagation eastward into the Andaman Sea. The generation location was chosen based on findings from several authors namely, Raju et al. [55] and Sun et al. [54] who produced comprehensive studies based on satellite imagery.

In the absence of in-situ data for model validation, other strategies were used to infer on the quality of the results. The phase speeds for long-lived mode- 1 waves were computed with an algorithm to detect the leading wave on a ISWs packet based on accelerations. The monthly averaged phase speeds calculated for the area of the Central Andaman Sea comprised between $94^{\circ}$ and $94.5^{\circ} \mathrm{E}$ (with water depths ranging from 2000 to $3500 \mathrm{~m}$ ) are within the range of observations. Model results provide values between 2.33 and $2.50 \mathrm{~m} / \mathrm{s}$ in line with observations and theoretical calculations presented by Tensubam et al. [52]. However, this study does not corroborate the finding from Tensubam et al. [52] regarding the seasonality of phase speeds. In their paper, Tensubam et al. [52] reported higher phase speeds in January/December in the SE Andaman Sea. They attribute this seasonal variability to changes in stratification and mixed layer depth. The model results show an increase in phase speed with increasing mixed layer depth with a correlation 0.62. In addition, the number of events seems correlated with the mixed layer depth. A negative correlation of -0.51 was obtained indicating that occurrence of ISWs is more likely during high-stratification periods. Figure 4 shows the dependence between phase speed, frequency of events and the mixed layer depth.

The time that it takes for a wave packet to hit a specific location can be derived either from the computed phase speed if it is assumed that there are no relevant gradients or by identifying the moment of generation and the moment when the leading wave of a packet is detected over a specific location. Using the first method and given that (i) according to Tensubam et al. [52] and theoretical approach the phase speed doesn't change too much for water depths larger than $1000 \mathrm{~m}$, (ii) the distance between source and the target location described in Section 3 is $100 \mathrm{~km}$, the average time that it takes for the leading wave to hit the site is $11 \mathrm{~h}$ and $39 \mathrm{~min}$. The interpacket distance computed using the same premises and the fact that the associated period is $12 \mathrm{~h}$ and $25 \mathrm{~min}$ is around $106 \mathrm{~km}$ well within 
other estimates such as Sun et al. [54] and Tensubam et al. [52]. To use the second method, the generation mechanism needs to be understood. Given the complexity of the generation process it is not always easy to identify the mechanism responsible for the generation. Magalhaes and da Silva [56] examined the characteristics of the ISWs propagating in the Central Andaman Sea with origin in 2 different areas: (i) south of Car Nicobar Island-the same location considered in this paper, and (ii) to the North, along $10^{\circ} \mathrm{N}$ with origin over in the Ten Degree Channel. For the first case, typical long-lived mode- 1 waves were identified with an interpacket distance of about $100 \mathrm{~km}$. Short scale mode-1wave tails were also identified. For waves generated in the Ten Degree Channel no long-lived mode- 1 waves were identified. The paper from Magalhaes and da Silva [56] then discusses the mechanism of generation of the mode- 2 waves that are generated in the Ten Degree Channel. For long-lived mode- 1 waves produced south of the Car Nicobar Island, Maxworthy [60] is probably the one that best fits the observations. The mechanism can be roughly described as follows: when ebb tidal currents flow westward over the shallow sill they generate a lee-wave depression to the west side of the sill. When the tidal currents reverse to weak flood tidal current flowing eastward, the lee-wave escapes over the sill and evolves into the ISW propagating to the east across the Andaman Sea. Therefore, the time to travel between the source and the target location can be computed as the being the time between slack over the generation site and the instant when the leading wave is detected at the output location $100 \mathrm{~km}$ to the east. Using this method, the computed time for the leading wave in a packet to travel from source to destination is $11 \mathrm{~h}$ and $32 \mathrm{~min}$ in close agreement with the previous estimation.
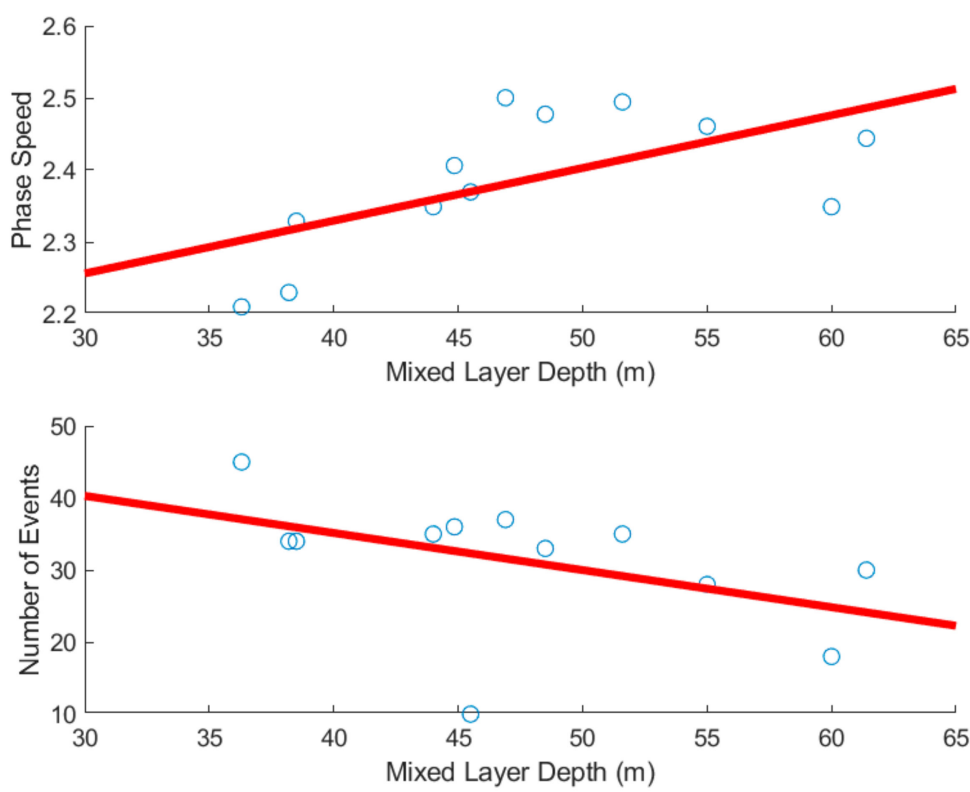

Figure 4. Monthly averaged mixed layer depth vs. monthly averaged phase speed (top) and frequency of events (bottom). The circles represent the model data while the red line provides the best linear fit.

To evaluate the relation between the tidal cycle and the amplitude of the current associated to ISWs it is useful to plot the tidal water levels at the generation location and currents at the target. Figure 5 shows the water levels at the generation location and the eastward current at $125 \mathrm{~m}$ depth over the output location $100 \mathrm{~km}$ to the east. It is clear the relation between the spring-neap tidal cycle with stronger currents being obtained during the spring stage. Actually, during the period with lowest tidal amplitudes shown in the figure (from 6 to 10 November) there are no events while later, from 10 November onwards, the eastward component of water current reaches values up to $1.5 \mathrm{~m} / \mathrm{s}$. 

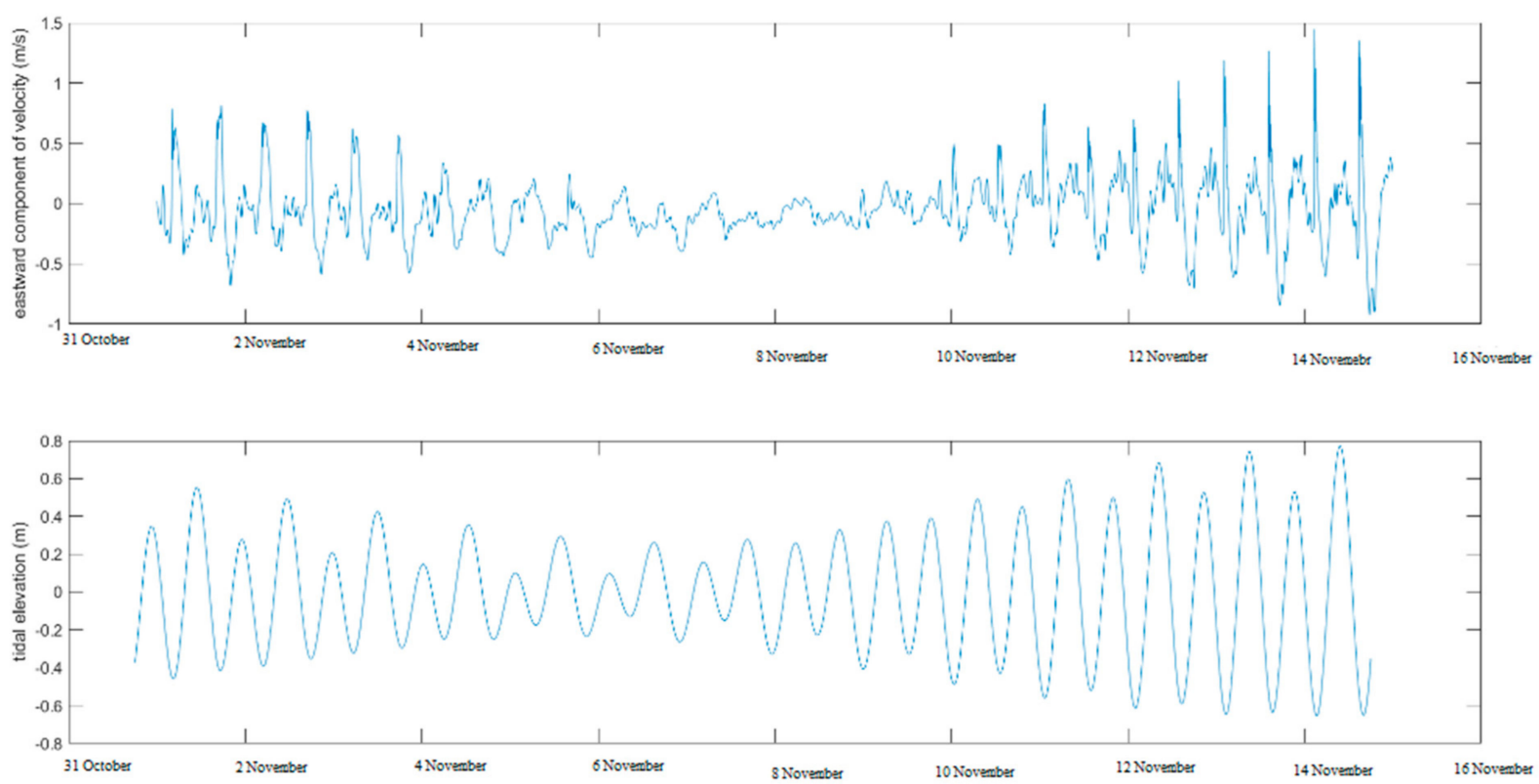

Figure 5. Eastward component of velocity at $125 \mathrm{~m}$ over the output location $100 \mathrm{~km}$ to the east of the generation (top) and low pass filtered sea level at generation location (bottom) for a small period in November 2015.

The results discussed so far contain valuable information for programming operations and for design regarding offshore industry. The model results proved to be reliable from the physical point of view and when compared to parameters such as phase speed and interpacket distance. To fully prove the validity of the model, available measurements of current speed and thermocline displacement are required. However, as a proof of concept these model results obtained for a long-term hindcast were used to derive metocean criteria by means of extreme value analysis. The currents associated to return periods of 1,10 , 50, 100 and 1000 years were derived by adjusting different distributions with different methods. The best estimate was obtained with the Generalised Pareto distribution adjusted by the maximum likelihood method. The results obtained are satisfactory when compared to the data although they seem to be a conservative estimate. It would be interesting in the future to compare model and in situ data in order to establish criteria at least to the lower return periods.

\section{Conclusions}

Following the methodology presented by Ali et al. [37] a 2D-V model was implemented in the Central Andaman Sea in order to simulate the propagation of ISW and derive relevant parameters for design and operations for the offshore industry. The model used realistic topography along the cross-section considered, and realistic boundary and initial conditions (tidal components, temperature and salinity). The model output was analyzed at two different locations arbitrarily chosen. To achieve the proposed goal the model ran for 10 years continuously. With the resolution used, the model took 10 wall clock hours to simulate a month using $362.9 \mathrm{GHz}$ Intel Xeon E5-2666 v3 processors or 50 days to run the whole hindcast. To our knowledge this was the first time that such and hindcast was produced for the purpose of deriving operational and design criteria.

The model was compared with available literature of the area, namely mixed layer depth, phase speed and related parameters such as interpacket distance. The results are in close agreement with the available data. In particular, the model has reproduced quite well the seasonal variability of the mixed layer depth and the phase speed. The frequency of events also shows a relevant correlation with mixed layer depth and stratification.

The phase speeds computed are in the range $2.21 \mathrm{~m} / \mathrm{s}$ in March when the mixed layer depth is at the minimum $(36.3 \mathrm{~m})$ and $2.5 \mathrm{~m} / \mathrm{s}$ in November that corresponds to the second 
highest value for the mixed layer depth $(58 \mathrm{~m})$. The average time that it takes for a wave to travel from generation location to a point $100 \mathrm{~km}$ to the east is about $11 \mathrm{~h}$ and $30 \mathrm{~min}$, implying an interpacket distance of $106 \mathrm{~km}$. The computation of such a time using two different methods shows that for depths larger than a certain threshold the phase speed is nearly independent of water depth.

The frequency of events is at maximum in March when the mixed layer depth in minimum. Physically this means that when the stratification is stronger the Baines [58] potential for generation is amplified and therefore the number of events is increased. Conversely, when the mixed layer depth is at maximum, the stratification is weaker and the number of events is lower. This is the case for June, July and August.

Monthly averaged maximum speeds were calculated based on event selection by using an acceleration threshold at $100 \mathrm{~m}$ depth. Most importantly the maximum speeds for every month were computed. There are significant differences between July to September and November to January. The lowest maximum speed was obtained for August $(0.22 \mathrm{~m} / \mathrm{s})$ while the highest value is $1.49 \mathrm{~m} / \mathrm{s}$ in November.

Finally, extreme value analysis was conducted on the time series of events by using the peaks over threshold method. The obtained series of peaks was fitted by using the maximum likelihood method to adjust a Generalised Pareto distribution. The currents associated to the return periods of 1, 10, 50, 100 and 1000 years range from $1.67 \mathrm{~m} / \mathrm{s}$ to $1.84 \mathrm{~m} / \mathrm{s}$.

The methodology presented to produce long-time series of currents related to the passage of ISWs signifies a valid tool to produce robust information for design and operations for offshore industry. In particular, the proposed methodology can be used in lieu of expensive metocean observation campaigns with limited time coverage. However, in order to have a reliable dataset a set of measurements is always required for validation purposes. The methodology proposed allows the derivation of extreme criteria. The present model has been validated for a limited number of parameters that does not include currents and thermocline displacements. Additional work is compulsory, including a full validation of the collected datasets that may be affected by ISWs associated with the offshore industry.

Author Contributions: Conceptualization, L.A., Y.G. and N.M.; methodology, L.A.; software, L.A., S.K. and P.F.; validation, L.A., N.M., S.K. and Y.B.; formal analysis, L.A.; investigation, Y.B., L.A.; resources, L.A., Y.G.; data curation, L.A., N.M. and S.K.; writing-original draft preparation, Y.B.; writing-review and editing, L.A., P.F., S.K. and N.M.; visualization, L.A.; supervision, Y.B.; project administration, L.A., and N.M.; funding acquisition, L.A., S.K. and P.F. All authors have read and agreed to the published version of the manuscript.

Funding: Funding support for this study was provided by Zhejiang University.

Institutional Review Board Statement: Not applicable.

Informed Consent Statement: Not applicable.

Data Availability Statement: The data can be available on suitable demand.

Acknowledgments: I am thankful to Zhejiang University for giving me the chance to study for my PhD under Yong Bai Supervision.

Conflicts of Interest: The authors declare no conflict of interest.

\section{References}

1. Apel, J.R. Principles of Ocean Physics; Academic Press: San Diego, CA, USA, 1987; 631p.

2. Jackson, C.; Da Silva, J.; Jeans, G. The Generation of Nonlinear Internal Waves. Oceanography 2012, 25, 108-123. [CrossRef]

3. Klymak, J.M.; Moum, J.N. Internal solitary waves of elevation advancing on a shoaling shelf. Geophys. Res. Lett. 2003, 30, 2045. [CrossRef]

4. Orr, M.H.; Mignerey, P.C. Nonlinear internal waves in the South China Sea: Observation of the conversion of depres-sion internal waves to elevation internal waves. J. Geophys. Res. 2003, 108, 3064. [CrossRef]

5. Ramp, S.; Tang, T.Y.; Duda, T.; Lynch, J.; Liu, A.; Chiu, C.-S.; Bahr, F.; Kim, H.-R.; Yang, Y.-J. Internal Solitons in the Northeastern South China Sea Part I: Sources and Deep Water Propagation. IEEE J. Ocean. Eng. 2004, 29, 1157-1181. [CrossRef] 
6. Shroyer, E.L.; Moum, J.N.; Nash, J.D. Observations of Polarity Reversal in Shoaling Nonlinear Internal Waves. J. Phys. Oceanogr. 2009, 39, 691-701. [CrossRef]

7. Lien, R.-C.; D’Asaro, E.A.; Henyey, F.; Chang, M.-H.; Tang, T.-Y.; Yang, Y.-J. Trapped Core Formation within a Shoaling Nonlinear Internal Wave. J. Phys. Oceanogr. 2012, 42, 511-525. [CrossRef]

8. Munk, W.H.; Wunsch, K. Abyssal recipes. II: Energetics of tidal and wind mixing. Deep-Sea Res. 1998, 45, 1977-2010. [CrossRef]

9. Egbert, G.D.; Ray, R.D. Significant dissipation of tidal energy in the deep ocean inferred from satellite altimeter data. Nature 2000, 405, 775-778. [CrossRef] [PubMed]

10. Bogucki, D.; Dickey, T.; Redekopp, L. Sediment resuspension and mixing by resonantly generated internal solitary waves. J. Phys. Oceanogr. 1997, 27, 1181-1196. [CrossRef]

11. Hosegood, P.; Bonnin, J.; Van Haren, H. Solibore-induced sediment resuspension in the Faeroe-Shetland Channel. Geophys. Res. Lett. 2004, 31, L09301. [CrossRef]

12. Bogucki, D.J.; Redekopp, L.G.; Barth, J. Internal solitary waves in the coastal mixing and optics 1996 experiment: Multimodal structure and resuspension. J. Geophys. Res. 2005, 110, C02024. [CrossRef]

13. Butman, B.; Alexander, P.; Scotti, A.; Beardsley, R.; Anderson, S. Large internal waves in Massachusetts Bay transport sediments offshore. Cont. Shelf Res. 2006, 26, 2029-2049. [CrossRef]

14. Reeder, D.B.; Ma, B.B.; Yang, Y.-J. Very large subaqueous sand dunes on the upper continental slope in the South China Sea generated by episodic, shoaling deep-water internal solitary waves. Mar. Geol. 2011, 279, 12-18. [CrossRef]

15. Reeder, D.B.; Duda, T.F.; Ma, B. Ocean 2008-MTS/IEEE Kobe TechnoOcean; IEEE: Piscataway, NJ, USA, 2008; Volume 1-3, pp. 65-172.

16. Kuperman, W.A.; Lynch, J.F. Shallow-Water Acoustics. Phys. Today 2004, 57, 55-61. [CrossRef]

17. Chiu, L.Y.S. Enhanced nonlinear acoustic mode coupling resulting froman internal solitary wave approaching a shelf break. J. Acoust. Soc. Am. 2013, 133, 1306-1319. [CrossRef]

18. Osborne, A.R.; Burch, T.L. Internal Solitons in the Andaman Sea. Science 1980, 208, 451-460. [CrossRef]

19. Wang, Y.-H.; Dai, C.-F.; Chen, Y.-Y. Physical and ecological processes of internal waves on an isolated reef ecosystem in the South China Sea. Geophys. Res. Lett. 2007, 34, 1-5. [CrossRef]

20. Decarlo, T.M.; Cohen, A.L.; Wong, G.T.F.; Shiah, F.-K.; Lentz, S.J.; Davis, K.A.; Shamberger, K.E.F.; Lohmann, P. Community production modulates coral reef $\mathrm{pH}$ and the sensitivity of ecosystem calcification to ocean acidification. J. Geophys. Res. Oceans 2017, 122, 745-761. [CrossRef]

21. Reid, E.C.; De Carlo, T.M.; Cohen, A.L.; Wong, G.T.; Lentz, S.J.; Safaie, A.; Davis, K.A. Internal waves influence the thermal and nutrient environment on a shallow coral reef. Limnol. Oceanogr. 2019, 64, 1949-1965. [CrossRef]

22. Duda, T.F.; Duda, T.F.; Lynch, J.F.; Irish, J.D.; Beardsley, R.C.; Ramp, S.R.; Chiu, C.S.; Yang, Y.J. Internal tide and nonlinear internal wave behavior at thecontinentaslope in the Northern South China Sea. IEEE J. Ocean. Eng. 2004, 20, 1105-1130. [CrossRef]

23. Yang, Y.J.; Tang, T.Y.; Chang, M.H.; Liu, A.K.; Hsu, M.K.; Ramp, S.R. Solitons northeast of Tung-Sha Island during the ASIAEXpilot studies. IEEE J. Ocean. Eng. 2004, 29, 1182-1199. [CrossRef]

24. Alford, M.H.; Peacock, T.; MacKinnon, J.A.; Nash, J.D.; Buijsman, M.C.; Centurioni, L.R.; Chao, S.-Y.; Chang, M.-H.; Farmer, D.M.; Fringer, O.B.; et al. The formation and fate of internal waves in the South China Sea. Nature 2015, 521, 65-69. [CrossRef] [PubMed]

25. Jackson, C.R. An Atlas of Internal Solitary-Like Waves and Their Properties, 2nd ed.; Prepared under Contract for Office of Naval Research, Code 322PO, Contract N00014-03-C-0176; Global Ocean Associates: Alexandria, VA, USA, 2004; 560p.

26. Hamad, H.; Bai, Y.; Ali, L. A risk-based inspection planning methodology for integrity management of subsea oil and gas pipelines. Ships Offshore Struct. 2020. [CrossRef]

27. Ali, L.; Bai, Y.; Jin, S. Risk Assessment and reliability analysis of subsea production Systems. In Proceedings of the ASME 2020 39th International Conference on Ocean, Offshore and Arctic Engineering, Online, 3-7 August 2020. [CrossRef]

28. Ali, L.; Nawaz, A.; Bai, Y. Numerical simulations of GFRP-Reinforced columns having polypropylene and polyvinyl alcohol fibers. Complexity 2020, 2020, 8841795. [CrossRef]

29. Ali, L.; Nawaz, A.; Iqbal, S.; Aamir Basheer, M.; Hameed, J.; Albasher, G.; Shah, S.A.R.; Bai, Y. Dynamics of Transit Oriented Development, Role of Greenhouse Gases and Urban Environment: A Study for Management and Policy. Sustainability 2021, 13, 2536. [CrossRef]

30. Ali, L.; Bai, Y.; Jin, S. Systematic measures to cope with offshore drilling hazards: An interpretive structural modeling approach. In Proceedings of the ASME 2020 39th International Conference on Ocean, Offshore and Arctic Engineering, Online, 3-7 August 2020. [CrossRef]

31. Ali, L.; Khan, S.; Bashmal, S.; Iqbal, N.; Dai, W.; Bai, Y. Fatigue Crack Monitoring of T-Type Joints in Steel Offshore Oil and Gas Jacket Platform. Sensors 2021, 21, 3294. [CrossRef]

32. Khan, S.; Khulief, Y.A.; Al-Shuhail, A.A. The effect of injection well arrangement on $\mathrm{CO}_{2}$ injection into carbonate petroleum reservoir. Int. J. Glob. Warm. 2018, 14. [CrossRef]

33. Khan, S.; Khulief, Y.A.; Al-Shuhail, A.A. Numerical modeling of the geomechanical behavior of Biyadh Reservoir undergoing $\mathrm{CO}_{2}$ injection. Int. J. Geomech. 2017, 17, 1-12. [CrossRef]

34. Khan, S.; Khulief, Y.A.; Al-Shuhail, A.A. Alleviation of pore pressure buildup and ground uplift during carbon dioxide injection into Ghawar Arab-D carbonate naturally fractured reservoir. Environ. Earth Sci. 2018, 77, 449. [CrossRef] 
35. Khan, S.; Khulief, Y.A.; Al-Shuhail, A.A. Effects of reservoir size and boundary conditions on pore-pressure buildup and fault reactivation during $\mathrm{CO}_{2}$ injection in deep geological reservoirs. Environ. Earth Sci. 2020, 79, 1-23. [CrossRef]

36. Khan, S.; Khulief, Y.; Al-Shuhail, A.; Bashmal, S.; Iqbal, N. The Geomechanical and Fault Activation Modeling during $\mathrm{CO}_{2}$ Injection into Deep Minjur Reservoir, Eastern Saudi Arabia. Sustainability 2020, 12, 9800. [CrossRef]

37. Ali, L.; Bai, Y.; Xu, Y. A methodology to derive design metocean internal wave current criteria for submarine structures. Ships Offshore Struct. 2020, 1-10. [CrossRef]

38. Da Silva, J.C.B.; Bujsman, M.C.; Magalhaes, J.M. Internal waves on the upstream side of a large sill of the Mascarene Ridge: A comprehensive view of their generation mechanisms and evolution. Deep-Sea Res. I 2015, 99, 87-104. [CrossRef]

39. Simmons, H.; Chang, M.-H.; Chang, Y.-T.; Chao, S.-Y.; Fringer, O.; Jackson, C.; Ko, D.S. Modeling and Prediction of Internal Waves in the South China Sea. Oceanography 2011, 24, 88-99. [CrossRef]

40. Jackson, C.R. An Empirical Model for Estimating the Geographic Location of Nonlinear Internal Solitary Waves. J. Atmos. Ocean. Technol. 2009, 26, 2243-2255. [CrossRef]

41. Zhang, Z.; Fringer, O.B.; Ramp, S.R. Three-dimensional, nonhydrostatic numerical simulation of nonlinear internal wave generation and propagation in the South China Sea. J. Geophys. Res. Space Phys. 2011, 116, C05022. [CrossRef]

42. Alford, M.H.; MacKinnon, J.A.; Nash, J.D.; Simmons, H.; Pickering, A.; Klymak, J.M.; Pinkel, R.; Sun, O.; Rainville, L.; Musgrave, R.; et al. Energy Flux and Dissipation in Luzon Strait: Two Tales of Two Ridges. J. Phys. Oceanogr. 2011, 41, 2211-2222. [CrossRef]

43. Fringer, O.; Gerritsen, M.; Street, R. An unstructured-grid, finite-volume, nonhydrostatic, parallel coastal ocean simulator. Ocean Model. 2006, 14, 139-173. [CrossRef]

44. Jeans, G.; Xiao, W.; Osborne, A.; Jackson, C.; Mitchell, D. The Application of Nonlinear Fourier Analysis to Soliton Quantification for Offshore Engineering. In Proceedings of the ASME 2017 36th International Conference on Ocean, Offshore and Artcic Engineering, OMAE2017, Trodheim, Norway, 25-30 June 2017.

45. Jeans, G.; Osborne, A.R.; Jackson, C.R. The Quantification of Soliton Current Profiles for Offshore Engineering. In Proceedings of the ASME 2018 37th International Conference on Ocean, Offshore and Artcic Engineering, OMAE2018, Madrid, Spain, 17-22 June 2018.

46. Buijsman, M.C.; McWilliams, J.C.; Jackson, C.R. East-west asymmetry in nonlinear internal waves from Luzon Strait. J. Geophys. Res. Space Phys. 2010, 115, 10057. [CrossRef]

47. Kernkamp, H.; Petit, H.A.; Gerritsen, H.; de Goede, E.D. A unified formulation for the three-dimensional shal-low water equations using orthogonal co-ordinates: Theory and application. Ocean Dyn. 2005, 55, 351-369. [CrossRef]

48. Marshall, J.; Adcroft, A.; Hill, C.; Perelman, L.; Heisey, C. A finite-volume, incompressible Navier Stokes model for studies of the ocean on parallel computers. J. Geophys. Res. Space Phys. 1997, 102, 5753-5766. [CrossRef]

49. Vitousek, S.; Fringer, O.B. Physical vs. numerical dispersion in nonhydrostatic ocean modeling. Ocean Model. 2011, 40, 72-86. [CrossRef]

50. Boyer, T.P.; Garcia, H.E.; Locarnini, R.A.; Zweng, M.M.; Mishonov, A.V.; Reagan, J.R.; Weathers, K.A.; Baranova, O.K.; Seidov, D.; Smolyar, I.V. World Ocean Atlas 2018. NOAA National Centers for Environmental Information. Dataset. 2018. Available online: https:/ / accession.nodc.noaa.gov/NCEI-WOA18 (accessed on 1 May 2021).

51. Egbert, G.D.; Erofeeva, S. Efficient Inverse Modeling of Barotropic Ocean Tides. J. Atmos. Ocean Technol. 2002, 19, 183-204. [CrossRef]

52. Tensubam, C.M.; Raju, N.J.; Dash, M.K.; Barskar, H. Estimation of Internal Solitary Wave Phase Speed in the Andaman Sea using multi-sattelite images. Remote Sens. Environ. 2021, 252, 112189. [CrossRef]

53. Da Silva, J.C.B.; Magelhaes, J.M. Internal ISWs in the Andaman Sea: A new look to an old problem. In Proceedings of the Remote Sensing of the Ocean, Sea Ice, Coastal Waters, and Large Water Regions 2016, Edinburgh, UK, 19 October 2016 ; pp. 1-13.

54. Sun, L.; Zhang, J.; Meng, J. A study of the spatial-temporal distribution and propagation characteristics of internal waves in the Andaman Sea using MODIS. Acta Oceanol. Sin. 2019, 38, 121-128. [CrossRef]

55. Raju, N.J.; Dash, M.K.; Dey, S.P.; Bhaskaran, P.K. Potential generation sites of internal solitary waves and their propagation characteristics in the Andaman Sea-A study based on MODIS true-colour and SAR observations. Environ. Monit. Assess. 2019, 191, 1-10. [CrossRef]

56. Magalhaes, J.M.; Da Silva, J.C.B. Internal Solitary Waves in the Andaman Sea: New Insights from SAR Imagery. Remote Sens. 2018, 10, 861. [CrossRef]

57. Alpers, W.; Wang-Chen, H.; Hock, L. Observation of internal waves in the Andaman Sea by ERS SAR. In Proceedings of the IGARSS'97. 1997 IEEE International Geoscience and Remote Sensing Symposium Proceedings. Remote Sensing-A Scientific Vision for Sustainable Development, Singapore, 3-8 August 1997; Volume 4, pp. 1518-1520.

58. Baines, P.G. On Internal Tide Generation Models. Deep Sea Research Part A. Oceanogr. Res. Pap. 1982, $29,307-338$.

59. Monterey, G.; Levitus, S. Seasonal Variability of Mixed Layer Depth for the World Ocean; NOAA Atlas NESDIS 14; U.S. Gov. Printing Office: Washington, DC, USA, 1997; 96p.

60. Maxworthy, T. A note on the ISWs produced by tidal flow over a three-dimensional ridge. J. Geophys. Res. 1979, 84, 338-346. [CrossRef] 